\title{
PERANAN EKOLOGI MAKROALGA BAGI EKOSISTEM LAUT
}

\author{
Oleh \\ Tri Handayani'
}

\begin{abstract}
ECOLOGICAL ROLE OF MACROALGAE FOR MARINE ECOSYSTEM. Macroalgae is an ecologically and economically important component in marine ecosystem. Ecologically, macroalgae has a role as a primary producer, food for other marine biota, provide shelter, nursery ground and carbon sink. Macroalgae contains photosynthetic pigments to be able to provide their own food and produce carbon dioxide for other marine biota (called primary productivity). Macroalgae is a food source, provide shelter and nursery ground for fish, gastropods (mollusks), crustaceans and sea urchins. Macroalgae also has the ability to to reduce the effects of global warming through carbon sink. Absorption of carbon emissions of anthropogenic activity by marine organisms are called as blue carbon. Therefore, macroalgae is ecologically important for the balancing of marine ecosystems sustainability.
\end{abstract}

\section{PENDAHULUAN}

Makroalga merupakan salah satu biota penyusun ekosistem laut yang memiliki manfaat, baik secara ekologis maupun secara ekonomis (Prathep et al., 2011; Chaves et al., 2013; Satheesh \& Wesley, 2012). Pemanfaatan makroalga secara ekonomis sudah bukan menjadi rahasia lagi. Makroalga atau rumput laut (sebutan oleh kalangan pengusaha dan pembudidaya makroalga) merupakan komoditas unggulan di bidang perikanan. Makroalga merupakan sumber penghasil fikokoloid (agar-agar, karaginan dan alginat) yang banyak dimanfaatkan untuk berbagai industri seperti industri makanan, kosmetik, farmasi, fotografi dan industri lainnya (Holdt \& Kraan, 2011). Makroalga juga merupakan sumber polisakarida bioaktif seperti ulvan, fukoidan, fukosantin, manitol,

\footnotetext{
1) Pusat Penelitian Oseanografi - LIPI
}

laminaran, caulerpenin yang bermanfaat untuk bahan senyawa obat (Zhuang et al., 1995; Murata \& Nakazoe, 2001; Deville et al., 2004; Holdt \& Kraan, 2011).

Manfaat makroalga secara ekologis memberikan dampak terhadap keseimbangan ekosistem laut dan secara tidak langsung memberikan dampak terhadap manusia terutama dalam bidang perikanan. Keanekaragaman makroalga yang tinggi akan berpengaruh terhadap produktivitas biologi yang tinggi di ekosistem. Makroalga sangat penting dalam perekrutan dan perlindungan bagi ikan dan kekerangan. Hasil perikanan tersebut akan terus berkelanjutan apabila keseimbangan ekosistem laut dapat terjaga kelestariannya (Okuda, 2008). Peranan makroalga secara ekologis terhadap ekosistemnya tidak banyak mendapatkan perhatian, karena peranan 
tidak memberikan dampak secara langsung bagi kehidupan manusia, padahal peranan makroalga secara ekologis juga sangat penting terutama bagi keseimbangan ekosistem.

Tulisan ini membahas peranan makroalga secara ekologis bagi ekosistem laut, yang berisi hubungan timbal balik antara makroalga dengan lingkungan dan makroalga dengan biota laut lainnya. Dengan meningkatnya pemahaman tentang arti penting peranan makroalga bagi ekosistem laut, diharapkan dapat meningkatkan kesadaran masyarakat untuk selalu menjaga kelestarian ekosistem laut, sehingga daya dukung ekosistem laut terhadap hasil perikanan dapat terus berkelanjutan.

\section{EKOSISTEM LAUT}

Ekosistem didefinisikan sebagai gabungan dari organisme hidup dan lingkungan, yang terdapat interaksi antara organisme satu dengan organisme lainnya dan terhadap lingkungannya. Ekosistem laut adalah bagian dari sistem akuatik terbesar di planet ini, meliputi lebih dari 70 persen permukaan bumi. Habitatnya membentuk area sistem yang luas mulai dari daerah dekat pantai yang produktif hingga dasar laut. Contoh ekosistem berdasarkan komunitas adalah ekosistem mangrove, padang lamun dan terumbu karang. Masing-masing ekosistem tersebut memiliki karakteristik yang berbeda-beda (Baker et al., 2009).

Terumbu karang adalah ekosistem perairan dangkal yang terdiri dari terumbu yang terbuat dari kalsium karbonat yang sebagian besar disekresikan oleh karang pembentuk terumbu dan makroalga yang berkapur. Terumbu karang menempati kurang dari $0,1 \%$ dari dasar perairan laut/samudera namun memainkan berbagai peran penting di seluruh daerah tropis, menampung keanekaragaman hayati tingkat tinggi serta menyediakan organisme dan jasa ekosistem utama seperti habitat perikanan, perlindungan pantai, dan perairan yang menarik untuk pariwisata (Jaap, 2000; Wild et al., 2011). Hutan mangrove merupakan suatu formasi hutan yang mampu tumbuh dan berkembang di daerah tropis dan subtropis pada lingkungan pesisir yang memiliki kondisi antara lain: berkadar garam sangat ekstrim, jenuh air, kondisi tanah yang tidak stabil dan anaerob yang selalu dipengaruhi oleh pasang surut (Pramudji, 2013). Padang lamun adalah suatu ekosistem yang terdiri dari asosiasi antara lamun (tumbuhan angiospermae/ berbunga yang dapat tumbuh dan berkembang di perairan laut) dengan organisme laut lainnya dan habitatnya (Hemminga \& Duarte, 2000; Duarte, 2000). Makroalga merupakan salah satu biota penyusun dari tiga ekosistem tersebut.

\section{PERANAN MAKROALGA SECARA EKOLOGIS}

Makroalga sebagai biota penyusun ekosistem laut tentunya memiliki peranan secara ekologis terhadap ekosistem tempat tumbuhnya. Peranan makroalga secara ekologis tersebut antara lain: 


\section{A. Sebagai Produsen Primer}

Makroalga memiliki peranan secara ekologis bagi ekosistem laut sebagai produsen primer dalam rantai makanan (Prathep et al., 2011). Makroalga mengandung pigmen fotosintetik sehingga dapat menyediakan makanan sendiri dengan bantuan sinar matahari dan nutrisi yang ada di air laut. Makroalga menempati zona intertidal di daerah pasang surut sampai kedalaman dimana $0,01 \%$ cahaya fotosintesis tersedia (Agarwal et al., 2016). Sebagai produsen primer, makroalga melakukan proses fotosintesis dan peristiwa ini sering kita sebut sebagai produktivitas primer. Meskipun makroalga memiliki proporsi kecil dalam menyumbang produktivitas primer di laut, tetapi makroalga menyumbang biomassa dan proporsi besar dalam produktivitas primer di ekosistem laut. Estimasi potensi produktivitas primer makroalga sangat penting untuk memahami peranan makroalga dalam ekosistem laut dan transfer energi melalui rantai makanan (Tait \& Sciel, 2010).

Produktivitas primer bervariasi berdasarkan kedalaman perairan. Kondisi tersebut disebabkan, karena perbedaan spesies atau perbedaan komposisi dan keragaman makroalga di perairan yang berbeda kedalamannya (Tait \& Sciel, 2010). Perbedaan produktivitas primer juga dapat terjadi, karena perbedaan kapasitas fotosintesis. Kapasitas fotosintesis makroalga di perairan pantai curam lebih rendah dibandingkan dengan di perairan pantai landai (Gomez et al., 1997; Skene, 2004). Makroalga di pantai landai memiliki biomasa yang lebih besar dari pada di pantai curam (Tait \& Schiel, 2010). Jumlah spesies makroalga di pantai landai lebih besar daripada di pantai curam. Hal ini menunjukkan potensi dari peran keanekaragaman hayati dalam meningkatkan produktivitas primer (Schiel, 2006). Makroalga tumbuh di zona mid-littoral pada pantai berbatu memiliki laju fotosintesis dan produktivitas primer lebih rendah daripada makroalga di zona infra-littoral (Gomez et al., 2005). Biomassa dan keragaman spesies dapat meningkatkan produktivitas primer makroalga (Bruno et al., 2005).

Aktivitas fotosintesis thallus makroalga dapat diukur dengan laju transpor elektron (electron transport rate/ETR) menggunakan fluoresensi amplitudo-pulsa termodulasi (pulse-amplitude modulated/PAM) (Enriquez \& Borowitzka, 2010; Migne et al., 2015). Produktivitas individu dan komunitas diukur dengan carbon fluxes dalam ruang tertutup. Terdapat perbedaan produktivitas primer di setiap lokasi dan musim, dimana produktivitas primer seluruh komunitas akan menurun jika dibandingkan dengan pengukuran produktivitas primer secara individual dari spesies dominan (Migne et al., 2015). 
Potensi produktivitas primer makroalga cukup tinggi. Produktivitas primer spesies makroalga akan berbeda pada populasi yang berbeda, contohnya adalah produktivitas primer Dictyopteris delicatula, kondisi ini diduga dipengaruhi oleh nutrisi perairan (Gaitan-Espitia, 2011). Di India, spesies makroalga yang paling produktif adalah Ulva lactuca dan $U$. intestinalis, selanjutnya adalah Entheromorpha prolifera dan Rhizoclonium grande. Hal ini terjadi karena U. lactuca dan $U$. intestinalis memiliki efisiensi maksimum dalam menyerap energi matahari (Chaudhuri \& Choudhury, 1994).

\section{B. Sebagai sumber makanan bagi biota lainnya}

Sebagai produsen primer dalam rantai makanan, makroalga merupakan sumber pangan bagi biota laut lainnya (herbivora) (Prathep et al., 2011). Pemangsaan makroalga oleh herbivora tidak selalu memberi pengaruh negatif bagi ekosistem, tetapi juga merupakan salah satu cara alami untuk menjaga keseimbangan ekosistem dengan cara mencegah terjadinya ledakan populasi makroalga di ekosistem (Filbee-
Dexter \& Scheibling, 2014). Ikan, bulu babi dan gastropoda umumnya menjadi pemangsa bagi makroalga (Duffy \& Hay, 1990).

Makroalga merupakan makanan utama bagi ikan laut herbivora. Sebanyak 5\% ikan merupakan ikan herbivora, tetapi hanya 30\% saja yang hidup di laut. Ikan laut herbivora tersebut umumnya hidup di terumbu karang (TalentinoPablico et al., 2007). Tempat hidup ikan herbivora di terumbu karang, menyebabkan interaksi tidak hanya antara makroalga dan ikan herbivora, tetapi juga terjadi interaksi segitiga antara makroalga, ikan herbivora dan karang (Hixon, 2015). Sebagian besar ikan laut herbivora merupakan anggota dari Famili Blennidae, Kyphosidae dan Siganidae. Sebagai contoh, makroalga hijau seperti Enteromorpha dan Ulva lebih disukai oleh Scartichthys viridis (Blennidae), Girella spp. (Kyphosidae), Sarpa salpa (Sparidae). Makroalga coklat seperti Sargassum dan Dictyota lebih disukai oleh Kyphosus spp. (Kyphosidae) dan Siganus spp. (Siganidae) (Talentino-Pablico et al., 2007). Jenis-jenis ikan herbivora yang memangsa makroalga dapat dilihat pada Tabel 1. 
Tabel 1. Makroalga yang umumnya dimakan oleh ikan (Talentino-Pablico et al., 2007).

\begin{tabular}{|c|c|c|}
\hline \multicolumn{2}{|c|}{ Makroalga } & Spesies Ikan Herbivora \\
\hline $\begin{array}{l}\text { Rhodophyta } \\
\text { Ceramiaceae } \\
\text { Corallinaceae } \\
\text { Gelidiaceae } \\
\text { Rhodomelaceae }\end{array}$ & $\begin{array}{l}\text { Ceramium } \\
\text { Corallina } \\
\text { Jania } \\
\text { Gelidium } \\
\text { Laurencia } \\
\text { Polysiphonia }\end{array}$ & $\begin{array}{l}\text { Sarpa salpa } \\
\text { Scartichthys spp. } \\
\text { Hermosilla azurea } \\
\text { Girella spp. } \\
\text { Siganus spp }\end{array}$ \\
\hline $\begin{array}{l}\text { Ochrophyta } \\
\text { Sargassaceae } \\
\text { Dictyotaceae }\end{array}$ & $\begin{array}{l}\text { Sargassum } \\
\text { Dictyota }\end{array}$ & $\begin{array}{l}\text { Acanthurus spp. } \\
\text { Naso spp. } \\
\text { Kyphosus spp } \\
\text { Holacanthus passer } \\
\text { Amphiprion spp. } \\
\text { Sapta salpa }\end{array}$ \\
\hline $\begin{array}{l}\text { Chlorophyta } \\
\text { Ulvaceae } \\
\text { Cladophoraceae }\end{array}$ & $\begin{array}{l}\text { Ulva } \\
\text { Enteromorpha } \\
\text { Cladophora }\end{array}$ & $\begin{array}{l}\text { Girella } \text { spp. } \\
\text { Sarpa salpa } \\
\text { Scartichthys viridis } \\
\text { Liza vaigiensis }\end{array}$ \\
\hline
\end{tabular}

Bulu babi merupakan biota bentik yang hidup di batuan, serta terumbu di zona subtidal dan merupakan salah satu herbivora pemangsa makroalga (Filbee-Dexter \& Scheibling, 2014). Pemangsaan makroalga oleh bulu babi perlu mendapatkan perhatian, terutama yang memangsa makroalga/rumput laut budidaya. Penelitian pemangsaan bulu babi terhadap makroalga telah banyak dilakukan dan umumnya merupakan makroalga pada daerah substropis (Norderhaug \& Christie, 2009; Filbee-Dexter \& Scheibling, 2014). Spesies bulu babi pemangsa makroalga dapat dilihat pada Tabel 2. 
Tabel 2. Makroalga sebagai sumber makanan bagi bulu babi.

\begin{tabular}{|c|c|c|c|}
\hline No & $\begin{array}{c}\text { Genus } \\
\text { Makroalga }\end{array}$ & Spesies bulu babi & Sumber Pustaka \\
\hline 1 & Laminaria & $\begin{array}{l}\text { Strongylocentrotus polyacanthus } \\
\text { S. franciscanus } \\
\text { S. droebachiensis } \\
\text { S. purpuratus } \\
\text { Evechinus chloroticus }\end{array}$ & $\begin{array}{l}\text { Watanabe \& Harrold, 1991; } \\
\text { Scheibling \& Anthony, 2001; } \\
\text { Lauzon-Guay \& Scheibling, } \\
\text { 2007; Norderhaug \& Christie, } \\
2009 .\end{array}$ \\
\hline 2 & Alaria & $\begin{array}{l}\text { S. franciscanus } \\
\text { S. droebachiensis }\end{array}$ & $\begin{array}{l}\text { Lauzon-Guay \& Scheibling, } \\
2007\end{array}$ \\
\hline 3 & Nereocystis & S. franciscanus & $\begin{array}{l}\text { Watanabe \& Harrold, 1991; } \\
\text { Watson \& Estes, 2011. }\end{array}$ \\
\hline 4 & Pterygophora & S. franciscanus & Watson \& Estes, 2011 \\
\hline 5 & Macrocystis & $\begin{array}{l}\text { S. franciscanus } \\
\text { S. purpuratus } \\
\text { Tetrapygus niger } \\
\text { Loxechinus albus } \\
\text { E. chloroticus }\end{array}$ & $\begin{array}{l}\text { Watanabe \& Harrold, 1991; } \\
\text { Vega et al., 2005; Vasquez et } \\
\text { al., } 2006 .\end{array}$ \\
\hline 6 & Lessonia & $\begin{array}{l}\text { L. albus } \\
\text { L. niger }\end{array}$ & $\begin{array}{l}\text { Vega et al., 2005; Vasquez et } \\
\text { al., 2006. }\end{array}$ \\
\hline 7 & Cystoceira & $\begin{array}{l}\text { Paracentrotus lividus } \\
\text { Arbicia lixula } \\
\text { Diadema antillarun }\end{array}$ & $\begin{array}{l}\text { Thibaut et al., 2005; } \\
\text { Hernandez et al., } \\
\text { Giakoumi et } \text { al., } 2008 \text {; }\end{array}$ \\
\hline 8 & Sargassum & $\begin{array}{l}\text { P. lividus } \\
\text { Diadema antillarum } \\
\text { Centrostephanus rodgersii }\end{array}$ & $\begin{array}{l}\text { Thibaut et al., 2005; } \\
\text { Hernandez et al., 2008. }\end{array}$ \\
\hline 9 & Ecklonia & $\begin{array}{l}\text { C. rodgersii } \\
\text { E. chloroticus }\end{array}$ & Johnson et al., 2005. \\
\hline 10 & Undaria & $\begin{array}{l}\text { Heliocidaris erythrogramma } \\
\text { S. nudus }\end{array}$ & $\begin{array}{l}\text { Tamaki et al., 2005; Valentine } \\
\text { \& Johnson, 2005; Watanuki } \\
\text { et al., 2010. }\end{array}$ \\
\hline 11 & Saccharina & S. nudus & Watanuki et al., 2010 \\
\hline
\end{tabular}

Makroalga merupakan salah satu sumber makanan bagi gastropoda. Setiap spesies gastropoda memiliki kegemaran makan makroalga yang berbedabeda. Gastropoda seperti Elysa sp. umumnya ditemukan dan memakan Caulerpa racemosa (Duffy \& hay,
1990). Gastropoda Euchelus asper lebih suka memakan makroalga Enteromorpha linza dibandingkan dengan Ulva lactuca dan Gelidium spp. Nerita oryzarum lebih suka memakan makroalga Ulva lactuca dibandingkan dengan Enteromorpha linza (Das et al., 2014). 


\section{Sebagai Tempat Perlindungan}

Makroalga dapat menjadi tempat perlindungan/habitat bagi biota laut berukuran kecil, antara lain ekinodermata, moluska dan krustasea (Okuda, 2008; Prathep et al., 2011). Sebagai contoh, makroalga Halimeda opuntia menjadi tempat perlindungan bagi bulu babi, krustasea, moluska dan polikaeta berukuran kecil. Hal ini terbukti dengan ditemukannya biota-biota laut tersebut di rumpun H. opuntia (pengamatan pribadi).

Makroalga yang tumbuh di antartika umumnya memiliki thallus berukuran besar dan menjadi tempat perlindungan bagi beberapa gastropoda, antara lain: Desmarestia antarctica, Desmarestia anceps, Desmarestia menzeisii, Gigartina skottbergii, Myriograme mangini, Plocamium cartilagineum dan Palmaria decipiens. Masing-masing makroalga tersebut menjadi tempat berlindung bagi gastropoda yang berbeda. D. menziesii menjadi tempat berlindung bagi gastropoda Skenella umbilicata dengan kepadatan dapat mencapai 28 individu per $100 \mathrm{~g}$ makroalga basah. Gigartina skottsbergii menjadi tempat berlindung bagi gastropoda
$S$. umbilicata dengan kepadatan hingga mencapai 41 individu per 100 gram makroalga basah. Sedangkan Plocamium cartilagineum menjadi tempat berlindung bagi gastropoda $S$. umbilicata, Eatoniella caliginosa dan Laevilacunaria antarctica dengan kepadatan masing-masing 37, 39 dan 8 individu per $100 \mathrm{~g}$ makroalga basah (Amsler et al., 2015).

\section{Sebagai Habitat Pengasuhan}

Makroalga merupakan koloni/ rumpun yang dimanfaatkan oleh biota laut sebagai habitat pengasuhan (Okuda, 2008; Prathep et al., 2011). Biota laut yang umum ditemukan berada di rumpun makroalga adalah ikan (Chaves et al., 2013). Makroalga Sargassum furcatum di Perairan Pulau Cabo Frio, Brazil menjadi habitat pengasuhan bagi beberapa jenis ikan antara lain: Diplodus argenteus, Haemulon aurolineatum dan Acanthurus bahianus (Ornellas \& Coutinho, 1998). Beberapa contoh spesies ikan yang dapat ditemukan di rumpun makroalga dan menjadikan makroalga sebagai habitat pengasuhan dapat dilihat pada Gambar 1. 

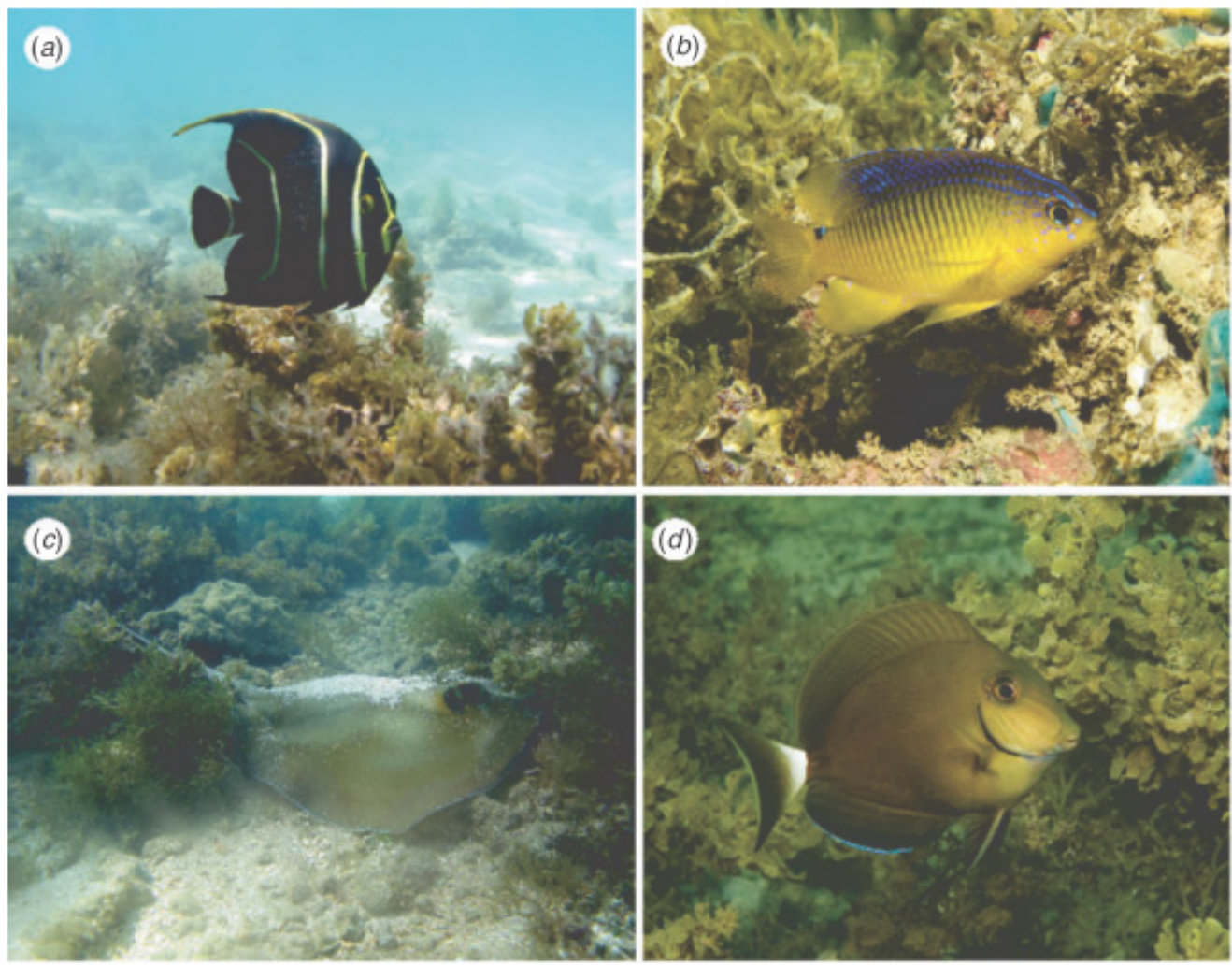

Gambar 1. Beberapa contoh spesies ikan yang dapat ditemukan di rumpun makroalga di perairan Tamandare, Timur Laut Brazil: (a) Pomacanthus paru, (b) Stegastes variabilis, (c) Dasyatis marianae dan (d ) Acanthurus bahianus (Chaves et al., 2013).

Peranan makroalga sebagai habitat pengasuhan, secara umum berkaitan dengan sumber makanan. Biota laut yang tumbuh dan berada di sekitar rumpun makroalga umumnya merupakan biota yang memangsa makroalga dan menjadikan makroalga sebagai habitat pengasuhan juga. Bulu babi merupakan salah satu biota yang menjadikan makroalga sebagai sumber makanan sekaligus sebagai habitat pengasuhan (Giakuomi et al.,
2012; Filbee-Dexter \& Scheibling, 2014).

\section{E. Sebagai Penyerap Karbon}

Saat ini, banyak penelitian yang tertarik untuk meneliti potensi tumbuhanlautsebagaipenyerapemisi karbon dari aktivitas antropogenik, yang dikenal dengan istilah "karbon biru" (blue carbon) (Krause-Jensen et al., 2018). Produsen primer di laut berkontribusi setidaknya $50 \%$ 
dari fiksasi karbon dunia dan dapat menyumbang sebanyak $71 \%$ dari seluruh karbon yang tersimpan di sedimen lautan. Alga dan tumbuhan tingkat tinggi, seperti mangrove dan lamun merupakan produsen primer lautan yang memiliki potensi dalam menyimpan karbon (Nellemann et al., 2009). Makroalga diketahui memiliki kemampuan menyerap karbon, sehingga dapat mengurangi pengaruh pemanasan global (Phang et al., 2008; Chung et al., 2011).

Penyerapan karbon oleh makroalga tidak hanya terjadi pada makroalga yang tumbuh secara alami, tetapi juga makroalga yang dibudidayakan (Chung et al., 2011). Makroalga seperti kelp (Macrocystis dan Laminaria) memiliki laju fotosintesis dan produktivitas yang tinggi yaitu $\geq 3.000$ g C per $\mathrm{m}^{2}$ per tahun $(30 \times 106 \mathrm{~g}$ per ha per tahun). Makroalga coklat (Ochrophyta) yang memiliki laju fotosintesis paling besar adalah Sargassum, Ascophyllum dan Fucus. Namun, makroalga merah (Rhodophyta) seperti Porphyra dan Palmaria memiliki laju fotosistesis yang lebih tinggi daripada makroalga coklat. Sedangkan makroalga hijau (Chlorophya) yang berthalus sederhana seperti Ulva dan Enteromorpha, juga memiliki laju asimilasi $\mathrm{CO}_{2}$ yang tinggi (Ritschard, 1992; Muraoka, 2004).
Program

penyerapan $\mathrm{CO}_{2}$ berbasis makroalga sangat penting untuk dimasukkan dalam memperhitungkan dampak potensial perubahan iklim terhadap pertumbuhan dan produksi makroalga yang digunakan. Harapannya, perubahan iklim akan memberikan dampak tidak hanya pada distribusi dan keanekaragaman makroalga, tetapi juga terhadap fisiologi makroalga (Chung et al., 2011).

\section{PENUTUP}

Makroalgamemiliki peranan secara ekologi bagi ekosistem laut yaitu sebagai produsen primer, tempat perlindungan, habitat pengasuhan, sumber makanan bagi biota laut lainnya, dan penyerap karbon sehingga dapat mengurangi dampak pemanasan global. Peranan makroalga ini memberikan dampak secara tidak langsung terhadap perikanan. Manfaat ekologi makroalga seringkali dipandang sebelah mata karena tidak memberikan dampak langsung terhadap kehidupan manusia. Pemahaman dan penyampaian informasi terkait pentingnya manfaat makroalga secara ekologi kepada masyarakat perlu mendapatkan dukungan dari pemerintah pusat dan daerah, dengan harapan kelestarian ekosistem laut dapat terjaga sehingga manfaatnya dapat terus berkelanjutan. 


\section{DAFTAR PUSTAKA}

Agarwal S., K. Banerjee, A. Saha, G. Amin and A. Mitra. 2016. Can seaweed be potential sink of carbon?. International Journal for Research in Applied Science \& Engineering Technology, 4 (8): 217-225.

Amsler M. O., Y. M. Huang, W. Engl, J. B. McClontock and C. D. Amsler. 2015. Abundance and diversity of gastropods associated with dominat subtidal macroalgar from the Western Antactic Peninsula. Polar Biol. DOI 10.1007/s00300-015-1681-4.

Baker, D. J., T. Bowman, J. Byrne, M. Connor, J. Cortina, J. Cortina, R. Dalrymple, L. Dierking, W. Eichbaum, J. Falk, A. Friedman, M. Grabowski, M. Nichol, W. Patzert, S. Pomponi, W. Reeburgh, and J. Sharp. 2009. Marine ecosystems and fisheries: balancing ecosystem sustainability and the socioeconomics of fisheries. Report of the ocean on the edge series produced by The Aquarium of The Pacific. 37 pp.

Bruno J. F., K. E. Boyer, J. E. Duffy, S. C. Lee, and J. S. Kertesz. 2005. Effects of macroalgal species identity and diversity on primary productivity in benthic marine communities. Ecol. Lett. 8:1165-1174.
Chaudhuri, A. B. and A. Choudhury. 1994. Mangroves of the Sundarbans, India.1, Bangkok, Thailand: IUCN. 247 pp.

Chaves, L. T. C., P. H. C. Pereira, and J. L. L. Feitosa. 2013. Coral reef fish associatiom with macroalgal beds on a tropical reef system in North-eastern Brazil. Marine and Freshwater Research. http://dx.doi.org/10.1071/ MF13054

Chung I. K., J. Beardall, S. Mehta, D. Sahoo and S. Stojkovic. 2011. Using marine macroalgae for carbon sequestration: a critical appraisal. J. Appl. Phycol, 23: 877-886. DOI 10.1007/s10811010-9604-9.

Das S., G. Deshmukhe and A. Dwivedi. 2014. Grazing on selected genera of green, red and brown macroalgae. Applied Ecology and Environmental Research, 12 (3): 717-725.

Deville C, J. Damas, P. Forget, G. Dandrifosse, and O. Peulen. 2004. Laminarin in the dietary fibre concept. J. Sci. Food Agric. 84:1030-1038.

Duarte, C. M. 2000. Marine biodiversity and ecosystem services: an elusive ink. J. Exp. Mar. Biol. Ecol. 250: 117-131.

Duffy J. E. and M. E. Hay. 1990. Seaweed adaptations to herbivory: chemical, tructural, and morphological defenses 
are often adjusted to spatial or temporal patterns of attack. BioScience, 40 (5): 368-375.

Enriquez, S., and M. A. Borowitzka. 2010. The use of the fluorescence signal in studies of seagrasses and macroalgae. In: Suggett, D. J., Prasil, O., Borowitzka, M. A. (Eds.), Chlorophyll a Fluorescence in Aquatic Sciences: Methods and Applications. Springer, pp. 187-208.

Filbee-Dexter K. and R. E. Scheibling. 2014. Sea urchin barrens as alternative stable states of collapsed kelp ecosystems. Mar. Ecol. Prog. Ser. 495: 1-25.

Gaitan-Espitia J. D. 2011. Matabolic rates and primary productivity of the marine macroalgae Dictyopteris delicatula in Taganga bay, Colombian Caribbean. Revista de Biologia Marina y Oceanografia. 46 (1): 73-77.

Giakoumi S., E. Cebrian, G. D. Kokkaris, E. Ballesteros and E. Sala. 2012. Relationships between fish, sea urchins and macroalgae: the structure of shallow rocky sublittoral communities in the cyclades, Eastern Mediterranean. Estuar. Coast Shelf Sci. 109: 1-10.

Gomez I., G. Weykam, H. Kloser, and C. Weincke. 1997. Photosynthetic light requirements, metabolic carbon balance and zonation of sublittoral macroalgae from King George Island (Antarctica). Mar. Ecol. Prog. Ser. 148:281-293.

Gomez I., F. Figueroa, P. Huovinen, N. Ulloa and V. Morales. 2005. Photosynthesis of the red alga Gracilaria chilensis under natural solar radiation in an estuary in southern Chile. Aquaculture 244: 369-382.

Hemminga, M. A. and C. M. Duarte. 2000. Seagrass Ecology. Cambrige University Press. Cambrige, UK. 298 pp.

Hernandez J. C., S. Clemente, C. Sangil and A. Brito. 2008. Actual status of the sea urchin Diadema antillarum populations and macroalgal cover in marine protected areas compared to a highly fished area (Canary Islands-eastern Atlantic Ocean). Aquat. Conserv. 18: 1091-1108.

Hixon M. A. 2015. Reff fishes, seaweeds, and corals: a complex triangle. In: C. Birkeland (ed.), Coral Reefs in the Anthropocene, 195 - 215. DOI 10.1007/978-94017-7249-5_10.

Holdt S.L. and S. Kraan. 2011. Bioactive compounds in seaweed: functional food applications and legislation. J. Appl. Phycol 23: 543-597. 
Jaap W. C. 2000. Coral reef restoration. Ecological Engineering 15: 345-364.

Johnson C. S. D. Ling, D. J. Rose, S. Shepherd and K. J. Miller. 2005. Establishment of the long-spined sea urchin (Centrostephanus rodgersii) in Tasmania: first assessment of potential threats to fisheries. Project Report. School of Zoology and Tamanian Aquaculture and Fisheries Institute, Hobart.

Krause-Jensen D., P. Lavery, O. Serrano, N. Marba, P. Masque, and C. M. Duarte. 2018 Sequestration of macroalgal carbon: the elephant in the Blue Carbon room. Biol. Lett. 14: 20180236. http://dx.doi.org/10.1098/ rsbl.2018.0236

Lauzon-Guay J. and R. E. Scheibling. 2007. Behaviour of sea urchin Strongylocentrotus droebachiensis grazing fronts: food-mediated aggregation and density-dependent facilitation. Mar. Ecol. Prog. Ser. 329: 191204.

Migne A., G. Delebecq, D. Davoult, N. Spilmont, D. Menu and F. Gevaert. 2015. Photosynthetic activity and productivity of intertidal macroalgae: in situ measurements, from thallus to community scale. Aquatic Botany, 123: 6-12.
Muraoka D. 2004. Seaweed resources as a source of carbon fixation. Bull. Fish Res. Agen Supplement 1:59-63.

Murata M, and J. Nakazoe. 2001. Production and use of marine algae in Japan. Jpn. Agr. Res. Q. 35:281-290.

Nellemann C., E. Corcoran, C. M. Duarte, L. Valdes, C. De Young, L. Fonseca, and G. Grimsditch. 2009. Blue carbon. A rapid response assessment. United Nations Environment Programme, GRID Arendal. www.grida.no.

Norderhaug K. M. and H. C. Christie. 2009. Sea urchin grazing and kelp re-vegetation in the NE Atlantic. Marine Biology Research, 5: 515-528.

Okuda, K. 2008. Coastal environment and seaweed-bed ecology in Japan. Kuroshio Science. 2 (1): 15-20.

Ornellas, A. B., and R. Coutinho. 1998. Spatial and temporal patterns of distribution and abundance of a tropical fish assemblage in a seasonal Sargassum bed, Cabo Frio Island, Brazil. Journal of Fish Biology 53: 198-208.

Phang S. M. P. E. Lim J. L. S. Ooi H. Y. Yeong W. S. Ng and F. C. Küpper 2008. Marine algae of Perak Island, Jarak Island and the Sembilan Group of Islands in the Straits of Malacca. 
Malaysian Journal of Science, 27 (3), 47-60.

Pramudji. 2013. Pengertian mangrove dan pegangan koleksi spesimen. Dalam: R. Pratiwi Manajemen Koleksi Rujukan Biota Laut. Pusat Penelitian Oseanografi LIPI, Jakarta. 197228.

Prathep A., S. Pongparadon A. Darakrai B. Wichachucherd and S. Sinutok. 2011. Diversity and distribution of seaweed at Khanom. Mu Ko Thale Tai National Park, Nakhon Si Thammarat Province, Thailand. Songklanakarin J. Sci. Technol. 33 (6): 633-640.

Ritschard R. L. 1992. Marine algae as a $\mathrm{CO} 2$ sink. Water Air Soil Pollut. 64 : 289-303.

Satheesh, S., and S. G. Wesley. 2012. Diversity and distribution of seaweeds in the Kudankulam coastal waters. South-Eastern coast of India. Biodiversity Journal 3(1):79- 84.

Scheibling R, E. and S. X. Anthony. 2001. Feeding, growth and reproduction of sea urchins (Strongylocentrotus droebachiensis) on single and mixed diets of kelp (Laminaria spp.) and the invasive alga Codium fragile ssp. Tomentosoides. Marine Biology, 139: 139-146.
Schiel D. R. 2006. Rivets or bolts? When single species count in the function of temperate rocky reef communities. J. Exp. Mar. Biol. Ecol. 338:233-252.

Skene K. R. 2004. Key differences in photosynthetic characteristics of nine species of intertidal macroalgae are related to their position on the shore. Can. J. Bot. 82:177-184.

Tait L. W. and D. R. Schiel. 2010. Primary productivity of intertidal macroalgal assemblages: comparison of laboratory and in situ photorespirometry. Marine Ecology progress Series, 416: 115-125.

Talentino-Pablico G., N. Bailly, R. Froese and C. Elloran. 2007. Seaweeds preferred by herbivorous fishes. J. Appl. Phycol. DOI 10.1007/ s10811-007-9290-4.

Tamaki H., H. Takahashi, A. Fukuya, M. Fukuda, S. Arai and S. Muraoka. 2005. The distributional patterns of Undaria pinnatifida (Harvey) Suringar and Seaurchins related to water velocity condition in Ogatsu bay, Miyagi Prefecture. Japan J. Phycol. 53: 131-135.

Thibaut T., S. Pinedo, X. Torras and E. Ballesteros. 2005. Longterm decline of the popullations of Fucales (Cystoceira spp. and Sargassum spp.) in the Alberes Coast (France, North-western 
Mediterranean). Mar. Pollut. Bull. 50: 1472-1489.

Valentine J. P. and C. R. Johnson. 2005. Persistance of sea urchin (Heliocidaris erythrogramma) barrens on the east coast of Tasmania: inhibition of macroalgal recovery in the absence of high densities of sea urchins. Bot. Mar. 48: 106-115.

Vásquez J. A., J. A. Vega, and A. H. Buschmann. 2006. Long term variability in the structure of kelp communities in northern Chile and the 1997-98 ENSO. J. Appl. Phycol. 18: 505-519

Vega J. M. A., J. A. Vasquez and A. H. Buschmann. 2005. Popullation biology of the subtidal kelp Macrocystis integrifolia and Lessonia trabeculata (Laminariales: phaeophyta) in an upwelling ecosystem of northern Chile: interannual variability and El Nino 199798. Rev. His. Nat. 78: 33-50.

Watanabe J. M. and C. Harrold. 1991. Destructive grazing by sea urchins Strongylocentrotus spp. in a Central California kelp forest: potential roles of recruitment, depth, and predation. Mar. Ecol. Prog. Ser. 71: 125-141.
Watanuki A., T. Aota, E. Otsuka, T. Kawai, Y. Iwahashi, H. Huwahara and D. Fujita. 2010. Restoration of kelp beds on an urchin barrens: removal of sea urchins by citizen divers in southwestern Hokkaido. Bull. Fish Res. Agency. 32: 83-87.

Watson J. and J. A. Estes. 2011. Stability, resillience, and phase shifts in rocky subtidal communities along the west coast of Vancouver Island, Canada. Ecol. Monogr. 81: 215-239.

Wild C., O. Hoegh-Guldberg, M. Naumann, M. F. ColomboPallotta, M. Ateweberhan, W. K. Fitt, R. Iglesias-Prieto, C. Palmer, J. C. Bythell, J. C. Ortiz, Y. Loya, and R. van Woesik. 2011. Climate change impedes scleractinian corals as primary reef ecosystem engineers. Mar. Freshw. Res. 62:205-215

Zhuang C, H. Itoh, T. Mizuno, and H. Ito. 1995. Antitumor active fucoidan from the brown seaweed, Umitoranoo (Sargassum thunbergii). Biosci Biotechnol. Biochem. 59:563567. 